\title{
ACOUSTIC EFFICIENCY RATING OF MUFFLERS
}

\author{
Olga Saulkina ${ }^{1 *}$ and Aleksei Bykov \\ B M STU, Power Engineering D epartment, 105005, M oscow, Russia
}

\begin{abstract}
The paper looks at basic approaches to evaluation of mufflers acoustic efficiency. The main focus is on such characteristics as transmission loss and combined transmission loss of the muffler. Comparison of acoustic efficiency of classic muffling elements was performed based on computational methods.
\end{abstract}

\section{Introduction}

There are two classes of mufflers according to the principle of operation: reactive mufflers with action based on reflecting sound waves passing through them, and dissipative (absorptive) mufflers containing a sound absorbing material which converts acoustic energy into heat energy. There are also combined reflection and absorption mufflers based on both muffling principles, and active mufflers, capable of adjusting to noise spectrum.

There are many works dealing with muffler design [1-16]. Muffler configuration choice depends on the installation's original noise spectrum and the required level of attenuation efficiency (acoustic efficiency). Until recently the designs were selected either empirically or through analytical calculations of simplified constructions. Application of the finite element method allows designing mufflers with complex configuration.

The aim of this study is to choose acoustic efficiency characteristic and compare against each other such typical muffling elements as expansion chamber, chamber with a dissipative material, and Helmholtz resonator chamber.

\section{Acoustic efficiency characteristics}

Acoustic efficiency of mufflers can be assessed using a number of characteristics, both split frequency and integral [1-3]. The choice of the characteristic for assessing noise attenuation efficiency is carried out by taking into account system properties needed for such an assessment.

The designed muffling system can be divided into three constituent parts: the gasdynamic noise source which is characterized by the value of mass velocity $V_{s}$ and impedance $Z_{s}$; the muffler, characterized by a quadripole with transmission matrix coefficients $T_{A}, T_{B}, T_{C}, T_{D}$; and the acoustic generator, characterized by radiation impedance $Z_{r}$ [3]. In this case it is expedient to use such parameter as inserted losses for assessing acoustic efficiency:

\footnotetext{
* Corresponding author: saulkinaolya@yandex.ru
} 


$$
I L=10 \lg \left(\left|P_{r 0}\right|^{2} /\left|P_{r}\right|^{2}\right)
$$

where $\left|P_{r 0}\right|,\left|P_{r}\right|$ is sound pressure spectral characteristics in a checkpoint, located at the distance $r$ from the outlet pipe end, for the exhaust system with or without a muffler, respectively.

Such parameter, as transmission loss, is also widely used:

$$
T L=10 \lg \left(P_{u}^{2} / P_{d}^{2}\right)
$$

where $P_{u}$ is sound pressure spectral characteristic of an incident wave at the muffler inlet; $P_{d}$ is sound pressure spectral characteristic of a wave that has passed through the muffler, in case of a matched (echoless) load at its output.

This relationship is determined only by muffler parameters $\left(T_{A}, T_{B}, T_{C}, T_{D}\right)$ and does not depend on the noise source $\left(V_{s}, Z_{s}\right)$ and acoustic generator $\left(Z_{r}\right)$ parameters [1].

Noise normalization is estimated by integral value, specifically, sound level, whereas efficiency characteristics, shown above, depend on frequency. From this point of view, it is necessary to assess the muffler acoustic efficiency using an integrated measure. The study [3] suggests using weighted overall transmission loss

$$
O T L=-10 \lg \int_{f_{1}}^{f_{2}} W^{2} 10^{-0.1 T L} d f
$$

$f_{1}, f_{2}$ is lower and higher boundary frequency, respectively, of the considered frequency range; $W$ is some weight function, for example, this can be the A-weighted scale correction, most widely used in acoustic engineering.

If the considered frequency range $F=f_{2}-f_{1}$ has the spectrum $P_{u}=$ const, this means that it is evenly distributed, $W=1$. In this case transmission loss is represented by frequency discrete values with step $\Delta f$, and if the number of discrete values is $N=F / \Delta f$, then the formula (3) is reduced to form [1]:

$$
O T L=-10 \lg \left(N^{-1} \sum_{i=1}^{N} 10^{-0.17 L_{i}}\right) .
$$

Below, as an example, we calculate overall transmission loss OTL as a criterion for assessment of noise reduction efficiency by chambers with classical muffling elements. Comparative analysis of the results obtained is also presented.

\section{Muffler design}

This study looks at the system of two mufflers with identical geometrical dimensions. The first muffler was represented by an expansion chamber, and the second muffler configuration was changing. Three variants of this muffler were studied: chambered, dissipative, and resonator muffler based on a concentric Helmholtz resonator. The reviewed mufflers were designed using the finite elements method in the Comsol Multiphysics software package in the frequency range $f_{1}=50 \mathrm{~Hz}$ and $f_{2}=1500 \mathrm{~Hz}$ with the step of $\Delta f=5 \mathrm{~Hz}$. Apart from muffler geometric size we assigned sound absorbing material properties for the dissipative muffler, such as material density and fiber diameter. 
Fig. 1 shows the mufflers' configurations and sound pressure distribution patterns in longitudinal axial section at $895 \mathrm{~Hz}$ frequency. As it follows from the presented patterns, the greatest sound reduction on this frequency is achieved using the dissipative muffler, and the least reduction is provided by the Helmholtz resonator.

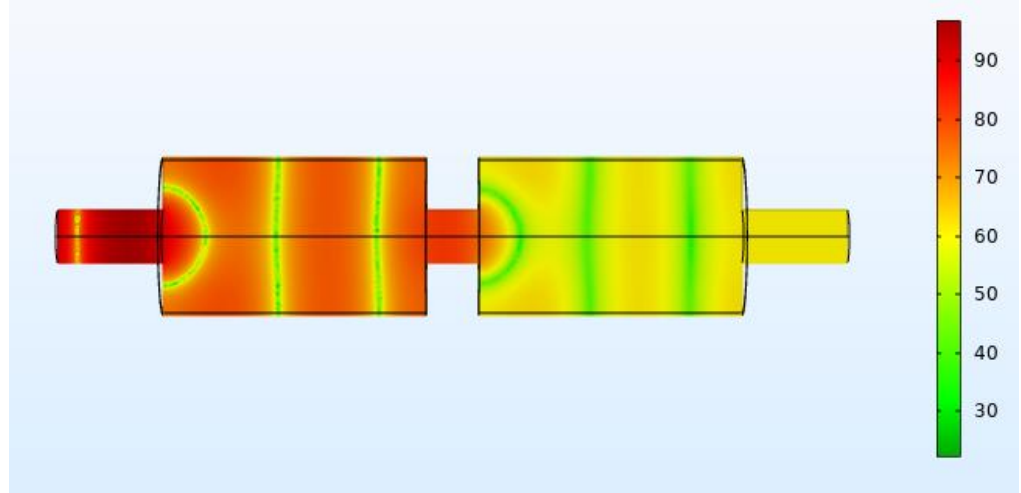

(a)

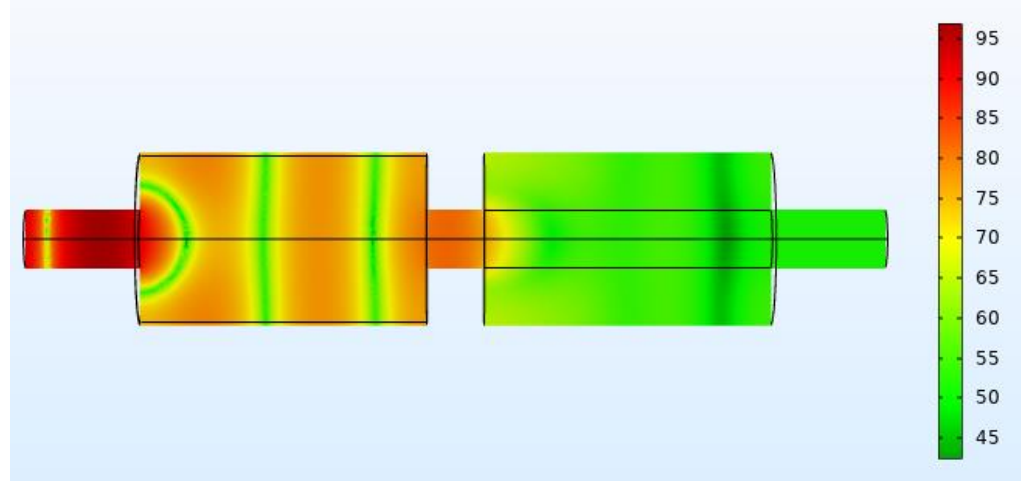

(b)

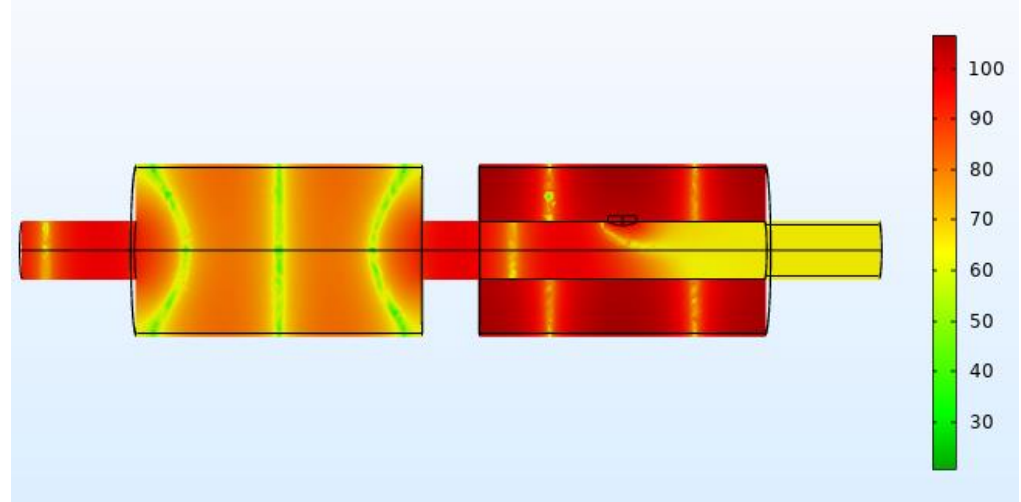

(c)

Fig. 1. Sound pressure levels distribution at $895 \mathrm{~Hz}$ frequency in longitudinal section with chambered (a), dissipative (b) and resonator (c) mufflers 


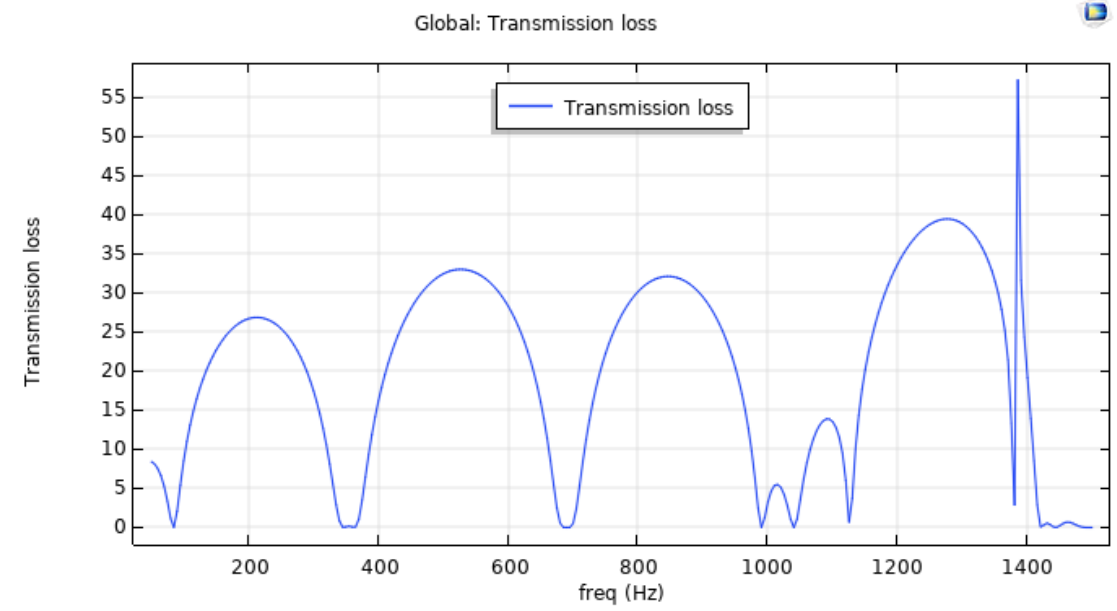

(a)

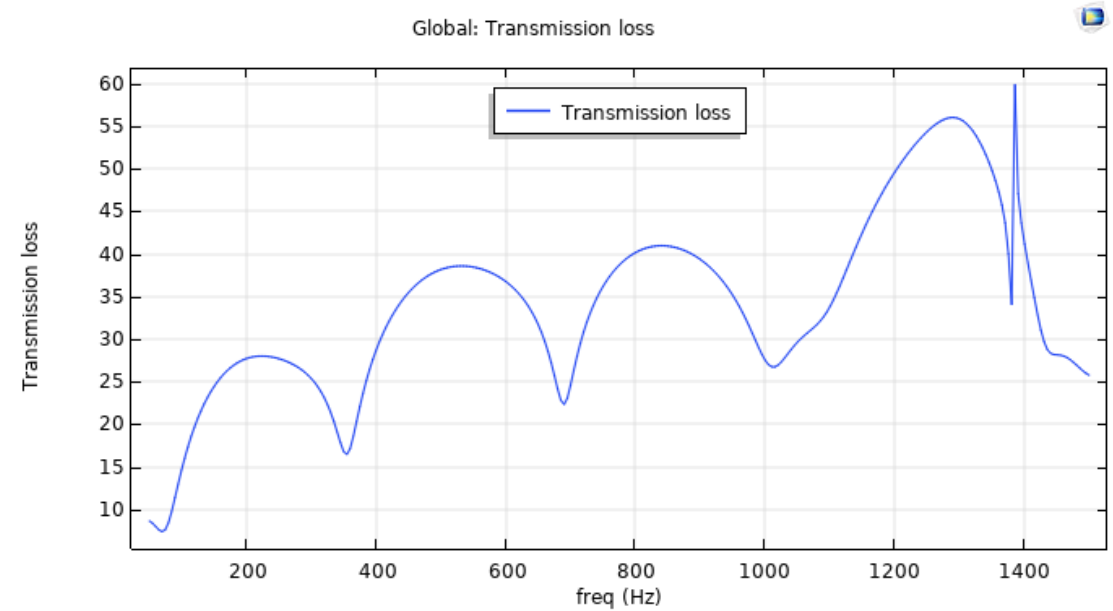

(b)

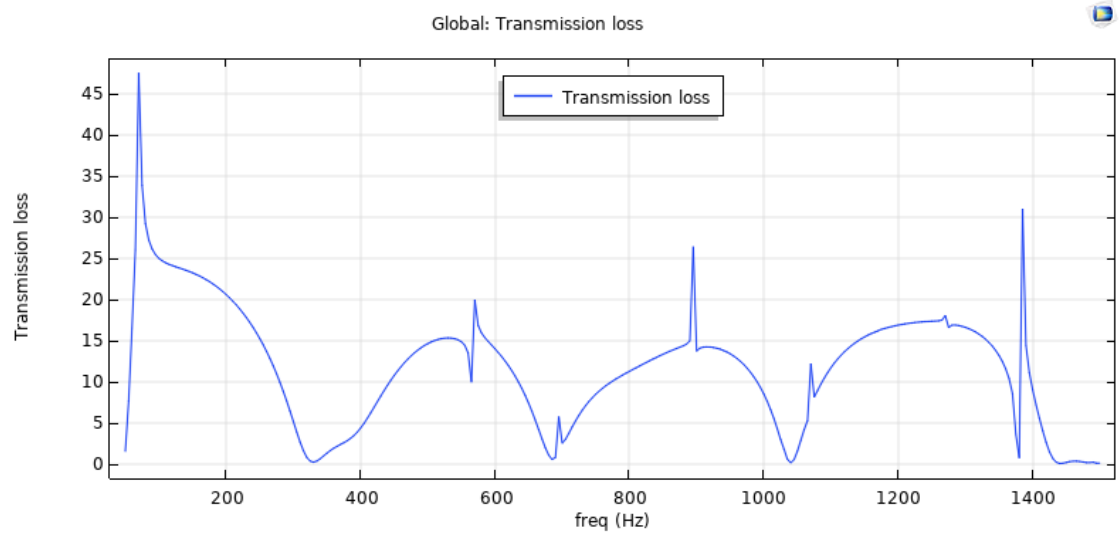

(c)

Fig. 2. Transmission loss for mufflers with expansion chamber (a), dissipative material (b), and Helmholtz resonator (c) 
Also, we obtained transmission loss $T L$ diagrams for mufflers with three reviewed configurations, shown in Fig. 2. After analyzing graphic dependencies it may be concluded that $T L$ values in a substantial way depends on frequency. Values contained between the maximum and minimum values vary in a wide range. In a large degree this is characteristic to chambered and resonator mufflers, and in a lesser degree to dissipative mufflers.

Overall transmission loss OTL, calculated according to formula (6): for the muffler with expansion chambers $-7.80 \mathrm{dBA}$; for the muffler with a chamber with dissipative material $22.02 \mathrm{dBA}$; for the muffler with a chamber with a Helmholtz resonator $-6.99 \mathrm{dBA}$.

According to the presented study availability of dissipative material significantly increases the muffler efficiency in general, especially on high frequencies. It also smooths the transmission loss curve. This results in high OTL values for this muffler. For this reason, if the original noise is evenly distributed with prevailing high frequencies, it is preferable to use a dissipative muffler to bring down the noise level. In its own turn, the muffler with a Helmholtz resonator, despite its respective smallest overall loss value among reviewed configurations, fits low frequency sound and allows selectively muffle individual high frequencies.

So, it is not entirely correct to follow only overall transmission loss values when designing a muffler. First of all, it is necessary to pay attention to the noise initial spectrum which is needed to be muffled, and then, based on it, to select an appropriate muffler configuration which would secure muffling noise in the most «problematic spots». Only after that numeric calculations should be performed, selecting the muffler geometric parameters so that the overall loss reaches the highest level. You should use weighted overall transmission loss $O T L_{W}(3)$, selecting weight function $\mathrm{W}$ with the consideration of distinctive properties of the muffled noise spectrum.

\section{Conclusion}

The calculations performed allow assessing acoustic efficiency of the reviewed muffler configurations and compare them to each other with the help of an integral parameter overall transmission loss. The muffler with dissipative material had the largest overall loss value in the frequency range of 50 to $1500 \mathrm{~Hz}$ among mufflers of identical geometric size. The muffler with a Helmholtz resonator had he smallest value.

In order to make integral ratings more objective, it is necessary to use weighted overall transmission loss $O T L_{W}$, where the weight function takes into account the original unmuffled noise spectrum shape. First of all, attention should be paid to the frequency range where noise reduction level should be the greatest.

\section{References}

1. A . I. Komkin, E. V. M alko, Criteria for assessing the acoustic efficiency of mufflers, Proceedings of the XIX session of the Russian A coustic Society. M oscow: GEOS, 2007. V. 3. P. 263-267, M oscow, Russia (2007)

2. A. I. Komkin, A coustical Physics. 56 (3), 373-379. (2010)

3. A. I. Komkin A .I. Development of modern methods for calculation and design of automobile mufflers with required characteristics, D octoral thesis: 01.04.06, B auman M oscow State Technical University, 411 p., M oscow, Russia (2012)

4. D. D. Davis, G. M. Stokes, D. M oor, G. L. Stevens, Theoretical and experimental investigation of mufflers with comments on engine exhaust muffler design, NA SA Technical Report 1192, 829-875. (1954) 
5. J. W. Sullivan, J ournal of the A coustical Society of A merica, 1979. 66 (3), 772-778, 19. (1979)

6. M . L. M unjal M .L, Acoustics of ducts and Mufflers, NY : W iley-Interscience, 328. (1987)

7. N. S. Dickey, A. Selament, J. M. N ovak, Journal of Sound and V ibration,1998, 211 (3), 435-448. (1998)

8. R. Glav, Journal of Sound and Vibration, 236 (4), 575-594. (2000)

9. S. N. Y. Gerges, R. J ordan, F. A. Thieme, J. L. B ento Coelho, Journal of the B razilian mechanical sciences and engineers, 27(2), 132-140. (2005)

10. R. Kirby, J ournal of Sound and Vibration, 325(3), 565-582. (2009)

11. G. Silva, M. N unes, Effect of effective length of the tube on transmission loss of reactive muffler, in Proceedings of InterN oise-2016. 10 p., Hamburg, Germany. (2016)

12. A. I. Komkin, M. A. M ironov, A . I. Bykov, A coustical Physics, 63 (4), 385-392. (2017)

13. A. I. Komkin, V. A. L'vov, N. S. Nesterov, Measurement Techniques, 60 (7), 736-741. (2017)

14. R. I. Rakhmatov, V. E. K rutolapov, V. N. Zuzov, Development of design solutions of exhaust system for gasdynamic noise reduction, in V ibroengineering Procedia, 2019, 25, 135-138. (2019)

15. V. V. Tupov, The calculation of channel end hole reflection ratio without a flange, in A IP Conference Proceedings. - A IP Publishing LLC, 2195(1):020034. (2019)

16. S. M. Sivachev, L. L. M yagkov, Thermomechanical Fatigue Analysis of Diesel Engine Piston: Finite Element Simulation and Lifetime Prediction Technique, International Conference on Industrial Engineering. Springer, Cham, M arch 2019, 109-117, Sochi, Russia (2019) 